\title{
Chronic Stress Induces Impairment of Spatial Working Memory Because of Prefrontal Dopaminergic Dysfunction
}

\author{
Kazushige Mizoguchi, ${ }^{1}$ Mitsutoshi Yuzurihara, ${ }^{1}$ Atsushi Ishige, ${ }^{1}$ Hiroshi Sasaki, ${ }^{1}$ De-Hua Chui, ${ }^{2}$ and \\ Takeshi Tabira² \\ ${ }^{1}$ Pharmacology Department, Central Research Laboratories, Tsumura and Company, Ami-machi, Inashiki-gun, Ibaraki \\ 300-1192, Japan, and 2Department of Demyelinating Disease and Aging, National Institute of Neuroscience, National \\ Center of Neurology and Psychiatry, Kodaira, Tokyo 187-8502, Japan
}

\begin{abstract}
Although the mechanism responsible for cognitive deficits in stress-related neuropsychiatric disorders has been obscure, prefrontal cortical (PFC) dopaminergic dysfunction is thought to be involved. In animals, the mesoprefrontal dopaminergic system is particularly vulnerable to stress, and chronic stress induces working memory impairment. However, the relation between the working memory impairment and altered dopaminergic activity in chronically stressed rats is unclear. Furthermore, the change of dopaminergic activity in the PFC induced by stress is thought to express as a stress response, not as a disorder of organic function. We have previously reported that chronic stress administered by water immersion and restraint for 4 weeks induces a organic disorder such as hippocampal neuronal degeneration. We therefore examined whether chronically stressed (4 weeks) and recovered (10 d) rats show a working memory impairment caused by reduced dopamine
\end{abstract}

(DA) transmission in the PFC, as suspected in the neuropsychiatric disorders. The stress impaired the spatial working memory evaluated by T-maze task and induced a marked reduction of DA transmission concomitant with an increase in DA D1 receptor density in the PFC. This memory impairment was sufficiently ameliorated by intra-PFC infusion of $10 \mathrm{ng}$ SKF 81297, a D1 receptor-specific agonist. Pretreatment with intraperitoneal injection of $20 \mu \mathrm{g} / \mathrm{kg} \mathrm{SCH} \mathrm{23390,} \mathrm{a} \mathrm{D1} \mathrm{receptor}$ antagonist, reversed the SKF 81297 response. These results indicate that chronic stress induces working memory impairment through a D1 receptor-mediated hypodopaminergic mechanism in the PFC. These findings provide important information for understanding of the mechanisms underlying PFC dysfunction in stress-related neuropsychiatric disorders.

Key words: chronic stress; working memory; prefrontal cortex; dopaminergic neuron; D1 receptor; cognitive deficit
Exposure to stress is known to precipitate or exacerbate many neuropsychiatric disorders such as depression, Parkinson's disease, schizophrenia, and others (Schwab and Zieper, 1965; Mazure, 1995). All these disorders involve a working memory deficit caused by prefrontal cortical (PFC) dysfunction (Mattes, 1980; Weinberger et al., 1986; Deutch, 1993; Fibiger, 1995). Several antidepressants increase dopamine (DA) levels in the PFC (Tanda et al., 1994), and raising the DA level in patients with Parkinson's disease with L-3,4-dihydroxyphenylalanine improves their working memory deficit (Lange et al., 1992). These findings suggest that a reduced dopaminergic transmission in the PFC is responsible for the working memory deficits in the neuropsychiatric disorders.

In animals, reduced PFC dopaminergic function or blockade of DA receptor in the PFC of monkeys and rats impairs working memory function (Brozoski et al., 1979; Simon et al., 1980; Bubser and Schmidt, 1990), which supports the observations in the neuropsychiatric disorders. In addition, an exposure to acute

\footnotetext{
Received Oct. 5, 1999; revised Nov. 22, 1999; accepted Nov. 24, 1999.

This work was partially supported by the Japan Health Science Foundation. We thank Drs. H. Kuribara, Y. Ikarashi, and Y. Maruyama of the Department of Neuropsychopharmacology (Tsumura) of Gunma University for advice and consultation on behavioral and neurochemical analyses and for their critical review of this manuscript. We also thank Mr. M. Hiruta for his construction of the T-maze apparatus.

Correspondence should be addressed to K. Mizoguchi, Pharmacology Department, Central Research Laboratories, Tsumura and Company, 3586 Yoshiwara, Ami-machi, Inashiki-gun, Ibaraki 300-1192, Japan. E-mail: mizoguchi_kazushige@ mail.tsumura.co.jp.

Copyright (C) 2000 Society for Neuroscience $\quad 0270-6474 / 00 / 201568-07 \$ 15.00 / 0$
}

stress in monkeys or rats has been reported to produce working memory impairment, which can be blocked by agents that prevent the increase in DA turnover (Arnsten and Goldman-Rakic, 1986; Murphy et al., 1996b) or that antagonize DA receptors (Murphy et al., 1996a; Arnsten and Goldman-Rakic, 1998), indicating a hyperdopaminergic mechanism. Similarly, chronic exposure to cold stress exhibits a large increase in the PFC DA metabolism after subsequent exposure to acute stress (Gresch et al., 1994). These stress responses are compatible with the facts that the mesoprefrontal dopaminergic system is particularly vulnerable to stress (Abercrombie et al., 1989) and that an overstimulation of DA D1 receptor in the PFC impairs the working memory (Zahrt et al., 1997). These findings lead to the hypothesis that there is an optimal DA receptor stimulation for proper PFC function (Zahrt et al., 1997; Arnsten and Goldman-Rakic, 1998), which indicates an important role for DA modulation of the neural processes within the PFC in working memory. However, these increased DA transmissions are thought to express as an acute stress response rather than as an organic disorder, because increased DA release in response to stress rapidly return to the basal level (Abercrombie et al., 1989; Gresch et al., 1994). In addition, although a chronic psychosocial stress also causes a delay in acquisition of working memory (Krugers et al., 1997), the role of the dopaminergic activity in the PFC is unclear. We have previously reported that chronic water immersion and restraint stress induces hippocampal neuronal degenerations (Mizoguchi et al., 1992), suggesting that certain stresses can produce organic disorders as in the case of immobilization (Watanabe et al., 1992). 
From these findings, we hypothesized that such a chronic stress will induce working memory impairment via a hypodopaminergic mechanism in the PFC, as suspected in the neuropsychiatric disorders.

In the present study, to test this hypothesis, we examined the effects of chronic stress on working memory performance and DA transmission in the PFC and searched for the contribution of the dopaminergic system to the stress-induced working memory impairment.

\section{MATERIALS AND METHODS}

Animals and stress exposure. All animal experiments were performed in accordance with our institutional guidelines after obtaining the permission of the Laboratory Animal Committee. Naive adult male Wistar rats (Japan Clea, Tokyo, Japan) weighing 300-350 gm were used. They were housed four per cage in a temperature $\left(22 \pm 2^{\circ} \mathrm{C}\right)$, humidity $(55 \pm 10 \%)$, and light (12 hr light/dark schedule; lights on at 7:00 A.M. and off at 7:00 P.M.)-controlled environment and were fed laboratory food and water. The procedure for stress exposure usually used in the study of stressinduced gastric lesions (Konturek et al., 1991; Brzozowski et al., 1993), with some modifications, was performed as previously described (Mizoguchi et al., 1992). Briefly, the animals were placed in a stress cage made of wire net and immersed to the level of the xiphoid process in a water bath $\left(21^{\circ} \mathrm{C}\right)$ for $2 \mathrm{hr}$. The animals were subjected to this stress session once a day for 4 weeks (chronic stress). To avoid the direct and acute influences of the stress and to evaluate the influences of chronic stress as an organic disorder, the animals were allowed a $10 \mathrm{~d}$ recovery period. In our preliminary experiments, gastric ulcer was not produced by one-time or chronic exposures. So, although relatively severe, this stress is not intense enough to produce a gastric ulcer.

Delayed-alternation task. Delayed-alternation tasks are widely considered to be particularly sensitive in demonstrating working memory impairment after the lesion of the PFC in all species of mammals (Markowitsch and Pritzel, 1977). In rodents, this task, usually performed in a T-maze (Moran, 1993; Zahrt et al., 1997), is one of the methods for evaluating spatial working memory most associated with the PFC (Van Haaren et al., 1985).

The delayed-alternation task using a T-maze was performed according to the method of Moran (1993), with some modifications. Briefly, the animal's food allowance was maintained at $\sim 90 \%$ of the normal intake until the end of the T-maze test. The animals were initially habituated to a T-maze [dimensions: stem arm, 75 length $(\mathrm{L}) \times 13$ width $(\mathrm{W}) \times 20$ height $(\mathrm{H}) \mathrm{cm}$; two branch arms, $50(\mathrm{~L}) \times 13(\mathrm{~W}) \times 20(\mathrm{H}) \mathrm{cm}$ each] for $4 \mathrm{~d}$ until they were readily eating food pellets at the end of each branch arm. After habituation, the animals were trained on the delayedalternation task. In the first trial (information run), the animal was placed in the starting box of the stem arm with the condition that one branch arm was blocked by a gray panel, and the animal was rewarded for entering either branch arm. Thereafter, for a total of 10 trials per session, animals were rewarded only if they entered the branch arm that was not chosen previously (correct choice in test run, win-shift strategy). At the end of the training trial, the animals demonstrating a rate of $>90 \%$ correct choices were selected and exposed to the stress for 4 weeks. After a 2 d recovery period, a guide cannula was implanted as mentioned below, and the animals were allowed $8 \mathrm{~d}$ to recover from the surgery. Ten trials for each delay time $(0,10,30$, and $60 \mathrm{sec})$ were then performed. After the information run, the animal was subjected to a delay and was allowed a test run. The number of errors per test run was recorded. We also observed anxiety-related behaviors (e.g., piloerection, freezing, urination, and defecation) during the task operations. The animals were rated on a three point scale whereby $0=$ normal behavior, $1=$ slight, and $2=$ severe evidence of anxiety-related behavior.

Infusion procedure. Infusion was performed according to the method of Zahrt et al. (1997) with minor modifications. Briefly, at a $2 \mathrm{~d}$ recovery period after a 4 week stress session, the animals were stereotaxically implanted with a guide cannula $(9-\mathrm{mm}$-long, $0.5 \mathrm{~mm}$ outer diameter; Bioanalytical Systems, West Lafayette, IN), which was anchored firmly to the skull by dental adhesive and acrylic resin, under pentobarbital anesthesia (45 mg/kg, i.p.). The brain atlas of Paxinos and Watson (1982) was used to determine the coordinates. The following coordinates relative to bregma were used for the cannula implantation in the PFC (anteroposterior, +3.2 ; lateral, \pm 1.2 ; depth from dura, 2.5). The animals were initially treated with Xylocaine (Fujisawa Pharmaceutical, Tokyo, Japan) to minimize pain and were monitored on a daily basis for signs of distress or infection.

Animals were initially adapted to a mock infusion protocol to minimize any stress associated with the procedure until the start of infusion experiments. After $8 \mathrm{~d}$ to recover from the surgery, the animals were gently restrained while the stylets were removed and replaced with infusion cannula (PC-12; Bioanalytical Systems) that extended $1 \mathrm{~mm}$ below the guide cannula. The animals received bilateral inf usions of SKF 81297 (Research Biochemicals, Natick, MA), a full D1 receptor agonist (activity comparable with DA itself; Andersen and Jansen, 1990), at a concentration of either 0 (vehicle), 1 , or $10 \mathrm{ng}$ in $0.5 \mu \mathrm{l}$ sterile saline at a rate of $0.1 \mu \mathrm{l} / \mathrm{min}$, using a microinf usion pump. Some animals received an intraperitoneal injection of $20 \mu \mathrm{g} / \mathrm{kg} \mathrm{SCH} 23390$ (Research Biochemicals), a DA D1 receptor-specific antagonist, dissolved in sterile saline 1 $\mathrm{hr}$ before the intra-PFC infusions. The cannula remained in place for 2 min after the completion of the infusion. Stylets were inserted back into the guide cannula, and behavioral testing was begun immediately after the infusion. Histological verification of cannula placement by dye infusion, performed at the end of the experiments, demonstrated the correct placement of the cannula in all animals.

Brain microdialysis. The DA release was measured by in vivo microdialysis in freely moving animals. The implantation of a guide cannula was performed as mentioned above. At a $10 \mathrm{~d}$ recovery period after a 4 week stress session, a bilateral dialysis probe (PC-12; tip length, $4 \mathrm{~mm}$, tip diameter, $0.2 \mathrm{~mm}$; Bioanalytical Systems) was inserted into the guide cannula, and Ringer's solution (in mmol/1: $\mathrm{Na}, 147$; K, 4.0; and $\mathrm{Ca}, 3.0$ ) was perfused at a rate of $0.6 \mu \mathrm{l} / \mathrm{min}$. After an equilibration period of 3 $\mathrm{hr}$, the perfusate was collected every $70 \mathrm{~min}$. To examine the response to stimuli, the $\mathrm{KCl}$ concentration was raised to $100 \mathrm{mmol} / \mathrm{l}$. The perfusates $(35 \mu \mathrm{l})$ were subsequently analyzed using an HPLC system equipped with a coulometric electrochemical detector (ECD-200; Eicom, Kyoto, Japan). A reverse-phase ODS column (CA-5; Eicom) was used with a mobile phase consisting of $82 \mathrm{mmol} / \mathrm{l}$ sodium phosphate, $\mathrm{pH}$. $6.0,800 \mathrm{mg} / \mathrm{l}$ sodium 1-octanesulfonate, $50 \mathrm{mg} / 1$ EDTA, and $180 \mathrm{ml} / 1$ methanol.

Contents of $\mathrm{DA}$ and its metabolites. The contents of DA, dihydroxyphenylacetic acid (DOPAC), and homovanillic acid (HVA) in the PFC were measured after the termination of the stress exposures at 1,2,3, and 4 weeks during the 4 week stress session and in the resting condition on day 10 of recovery. The measurement was performed according to the method of Takahashi et al. (1993), with some modifications. Briefly, the animals were killed by microwave irradiation at $9.0 \mathrm{~kW}$ for $1.1-1.3 \mathrm{sec}(10$ kW microwave device; New Japan Radio, Tokyo, Japan), and the PFC regions were dissected. The tissues were homogenized in $0.2 \mathrm{ml}$ of 100 $\mathrm{mmol} / 1$ perchloric acid solution containing $100 \mathrm{ng}$ of isoproterenol as an internal standard. The homogenate was centrifuged at $20,000 \times g$ for 30 $\mathrm{min}$, and the supernatant was filtrated with a $0.45 \mu \mathrm{m}$ membrane. The filtrate $(50 \mu \mathrm{l})$ was then injected into the HPLC system. A reverse-phase ODS column (MA-5; Eicom) was used with a mobile phase consisting of $44.2 \mathrm{mmol} / 1$ sodium citrate- $39.8 \mathrm{mmol} / 1$ sodium acetate, $\mathrm{pH} .3 .5,200$ $\mathrm{mg} / 1$ sodium 1-octanesulfonate, $5 \mathrm{mg} / 1$ EDTA, and $160 \mathrm{ml} / 1$ methanol.

Binding assay. On day 10 of recovery after a 4 week stress session, the animals were killed by decapitation, and the PFC was quickly dissected on an ice plate, immediately frozen on dry ice, and stored at $-80^{\circ} \mathrm{C}$. On the day of the experiment, the tissues were homogenized in ice-cold $1 \mathrm{ml}$ $50 \mathrm{mmol} / \mathrm{l}$ Tris- $\mathrm{HCl}$, pH. 7.4, containing $120 \mathrm{mmol} / \mathrm{l} \mathrm{NaCl}, 5 \mathrm{mmol} / 1$ $\mathrm{KCl}, 1 \mathrm{mmol} / 1 \mathrm{MgCl}_{2}$, and $1 \mathrm{mmol} / 1 \mathrm{CaCl}_{2}$ with a Teflon-glass homogenizer. The homogenates were centrifuged at $1000 \times g$ for $5 \mathrm{~min}$. The supernatants were centrifuged three times at $20,000 \times g$ for $20 \mathrm{~min}$ (resuspending the pellet each time in $1 \mathrm{ml}$ of the above buffer). The resultant pellet was resuspended, and aliquots of the suspensions were used for the determination of protein concentration according to Lowry's methods (Lowry et al., 1951).

DA D1 receptor binding assay was performed in duplicate according to the methods of Billard et al. (1984) and Bossé and Di Paolo (1996). Briefly, membrane preparations $(100 \mu \mathrm{g}$ of protein in a final volume of 1 $\mathrm{ml}$ ) were incubated with various concentrations of $\left[{ }^{3} \mathrm{H}\right] \mathrm{SCH} 23390$ (specific activity, $83 \mathrm{Ci} / \mathrm{mmol}$; Amersham Pharmacia Biotech, Tokyo, Japan) in the above buffer at $37^{\circ} \mathrm{C}$ for $20 \mathrm{~min}$. The reaction was terminated by separation of the free from bound radioligand by rapid vacuum filtration through a Whatman GF/B filter. Each filter was washed three times with $3 \mathrm{ml}$ of ice-cold $50 \mathrm{mmol} / \mathrm{l}$ Tris- $\mathrm{HCl}, \mathrm{pH}$. 7.4, containing $1 \mathrm{mmol} / 1$ $\mathrm{MgCl}_{2}$. Nonspecific binding was defined by the addition of $1 \mu \mathrm{mol} / 1$ unlabeled SCH 23390. The trapped radioactivity was counted in $6.0 \mathrm{ml}$ of Cleasol I scintillation fluid (Nakalai tesque, Osaka, Japan) by liquid scintillation counter (LS-5000; Beckman) at an efficiency of $45 \%$. The 
saturation binding data were plotted by Schatchard analysis, and the maximal number of binding sites $\left(B_{\text {max }}\right)$ and the dissociation constant $\left(K_{\mathrm{d}}\right)$ were calculated.

Immunohistochemistry. On day 10 of recovery after a 4 week stress session, immunostaining for tyrosine hydroxylase $(\mathrm{TH}$; tyrosine 3-monooxygenase; EC 1.14.16.2), the rate-limiting enzyme in catecholamine biosynthesis, was performed according to the method of Piazza et al. (1996). Briefly, the animals were anesthetized with pentobarbital Na (45 $\mathrm{mg} / \mathrm{kg}$, i.p.) and were perfused transcardially with $100 \mathrm{ml}$ of $0.1 \mathrm{~mol} / \mathrm{l}$ phosphate-buffered and heparinized saline, $\mathrm{pH}$. 7.4, followed by $300 \mathrm{ml}$ of $4 \%$ paraformaldehyde in $0.1 \mathrm{~mol} / 1$ phosphate buffer, $\mathrm{pH}$. 7.4. The brains were post-fixed for $24 \mathrm{hr}$ at $4^{\circ} \mathrm{C}$ in the same fixative and cryoprotected in $30 \%$ sucrose before being frozen in powdered dry ice. The frozen tissues were stored at $-80^{\circ} \mathrm{C}$. Sections $(30 \mu \mathrm{m})$ were cut using a freezing microtome. Free-floating tissue sections were rinsed three times

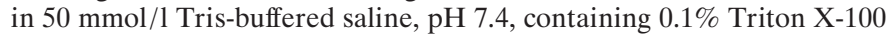
(TBST). Endogenous peroxidase activity was blocked using $3 \%$ hydrogen peroxide in TBST, followed by incubation with $10 \%$ normal rabbit serum (NRS) in TBST for $30 \mathrm{~min}$. The sections were then incubated overnight at room temperature with monoclonal mouse antibody against $\mathrm{TH}$ (Boehringer Ingelheim Bioproducts, Heidelberg, Germany), diluted 1:300 in TBST containing 1\% NRS. After incubation, the sections were washed three times with TBST and were incubated for $1 \mathrm{hr}$ at room temperature with biotinylated rabbit anti-mouse $\mathrm{IgG}$ (Vector Laboratories, Burlingame, CA), diluted 1:200 in TBST containing 1\% NRS. The sections were washed and finally incubated with avidinbiotin-peroxidase complex (Vector Laboratories) for $1 \mathrm{hr}$ at room temperature. Control sections, in which the mouse anti-TH antibody was replaced with NRS at the same dilution, were routinely processed together with the sections of interest. The peroxidase was visualized using $0.05 \%$ diaminobenzidine hydrochloride and $0.005 \%$ hydrogen peroxide. TH-positive cells were counted in the ventral tegmental area (VTA) under a microscope on three sections for each animal, with an interval of $100 \mu \mathrm{m}$ between sections.

Statistics. The differences in the T-maze performance were analyzed using a factorial ANOVA. The DA releases were analyzed using a one-way or two-way ANOVA. The contents of DA, DOPAC, and HVA were analyzed using repeated measures one-way ANOVA. Individual between-group comparisons were performed using Fisher's Protected Least Significant Difference test. The differences in the receptor-binding study and in the number of DA neurons were analyzed using unpaired $t$ test.

\section{RESULTS}

\section{Experiment 1: effects of chronic stress, intra-PFC infusion of SKF 81297, and reversal of SKF 81297 response with SCH 23390 on delayed- alternation performance}

The delayed-alternation performance (Fig. 1) under the no-delay condition was not affected by chronic stress exposure or agent treatments. However, chronically stressed rats showed a significantly reduced performance as compared with naive nonstressed rats under all delay conditions $\left(10 \mathrm{sec}, F_{(10,99)}=8.91, p<0.001\right.$; $30 \mathrm{sec}, F_{(10,99)}=6.48, p<0.001 ; 60 \mathrm{sec}, F_{(10,99)}=6.62, p<$ $0.001)$. It has been appreciated that DA has a beneficial influence on the spatial working memory functions of the PFC in monkeys (Brozoski et al., 1979) and in rats (Simon, 1980; Bubser and Schmidt, 1990). Several studies have identified the importance of D1 receptor mechanisms in this response (Sawaguchi and Goldman-Rakic, 1991; Seamans et al., 1995). Therefore, we then examined the improving effect of D1 receptor stimulation in the PFC on the stress-induced impairment of performance. Bilateral infusion of $1 \mathrm{ng}$ SKF 81297 into the PFC of the chronically stressed rats caused a significant improvement of the performance at 10 and $30 \sec \left(F_{(10,99)}=6.48 ; p<0.05\right.$, respectively $)$, but not at $60 \mathrm{sec}$ delay conditions. Intra-PFC infusion of $10 \mathrm{ng}$ SKF 81297 sufficiently and significantly improved the performance in all delay conditions $\left(10 \mathrm{sec}, F_{(10,99)}=8.91, p<0.001 ; 30 \mathrm{sec}\right.$, $\left.F_{(10,99)}=6.48, p<0.001 ; 60 \mathrm{sec}, F_{(10,99)}=6.62, p<0.001\right)$. These

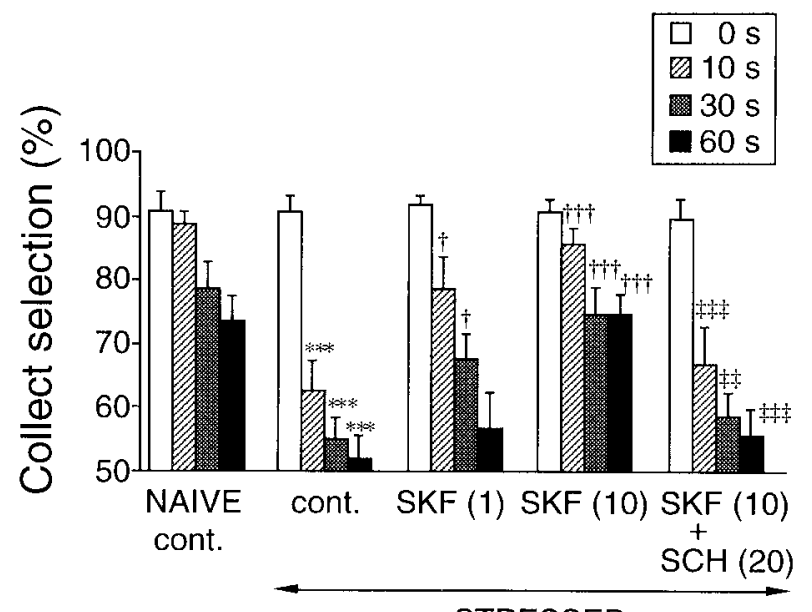

STRESSED

Figure 1. Effects of chronic stress and bilateral infusion of DA D1 receptor agonist (SKF 81297, SKF) into the PFC, and intraperitoneal injection of D1 receptor antagonist (SCH 23390, SCH) on the performance of the delayed-alternation task with no-delay $(0 \mathrm{sec})$ or several delay conditions $(10,30$, and $60 \mathrm{sec})$. The values in parentheses are in nanograms per $0.5 \mu \mathrm{l}$ for SKF 81297 or in micrograms per kilogram for $\mathrm{SCH} 23390$. Each column is the mean \pm SEM of 10 rats per group. ${ }^{* *} p<$ 0.001 , significant difference from naive nonstressed control (cont., vehicleinf used, and injected) rats; $\uparrow p<0.05, \dagger \dagger p<0.01, \dagger \dagger p<0.001$, significant difference from stressed control (cont.) rats; $\ddagger t p<0.01, \ddagger \dagger t p<0.001$, significant difference from stressed and SKF (10)-infused rats.

improving effects of $10 \mathrm{ng}$ SKF 81297 were reversed by the pretreatment with intraperitoneal injection of $20 \mu \mathrm{g} / \mathrm{kg} \mathrm{SCH}$ 23390 , the specific DA D1 receptor antagonist $\left(10 \mathrm{sec}, F_{(10,99)}=\right.$ $8.91, p<0.001 ; 30 \mathrm{sec}, F_{(10,99)}=6.48, p<0.01 ; 60 \mathrm{sec}, F_{(10,99)}=$ $6.62, p<0.001)$. The inf usion and injection of vehicle (control) or $\mathrm{SCH} 23390$ injection alone into the stressed and naive nonstressed rats and the infusion of $10 \mathrm{ng}$ SKF 81297 into the naive rats did not affect the performance (data not shown). No anxietyrelated behavior was observed in any experimental group (almost all animals had a score of 0 ).

\section{Experiment 2: neurochemical and neurobiological studies on DA neurons in the chronically stressed rats} $D A$ release

The DA release in the PFC under the basal condition and $\mathrm{KCl}$ stimulative condition was compared between chronically stressed and naive nonstressed rats (Fig. 2). The basal DA release in the chronically stressed rats was much lower, approximately one-fifth of the control level, than that in the naive nonstressed rats $\left(F_{(3,19)}=33.6 ; p<0.01\right)$. A remarkable increase in DA release was observed in the naive nonstressed rats on perfusion of high $\mathrm{KCl}\left(F_{(3,19)}=33.6 ; p<0.001\right)$. However, no KCl-induced increase in DA release was observed in the chronically stressed rats $\left(F_{(3,19)}=33.6 ; p<0.001\right)$. The two-way ANOVA revealed a significant stress effect $\left(F_{(3,19)}=33.6 ; p<0.001\right)$, a significant time effect $\left(F_{(6,19)}=50.9 ; p<0.001\right)$, and a significant stress-bytime interaction effect $\left(F_{(18,19)}=20.3 ; p<0.001\right)$.

\section{Contents of $D A$ and its metabolites}

The time courses of change in the contents of DA and its metabolites DOPAC and HVA in the PFC during the chronic stress session are presented in Table 1 . At week 1, both DOPAC and HVA levels, but not the DA level, were significantly increased $\left(\mathrm{DOPAC}, F_{(4,40)}=4.29, p<0.01 ; \mathrm{HVA}, F_{(4,40)}=4.18, p<0.01\right)$. 


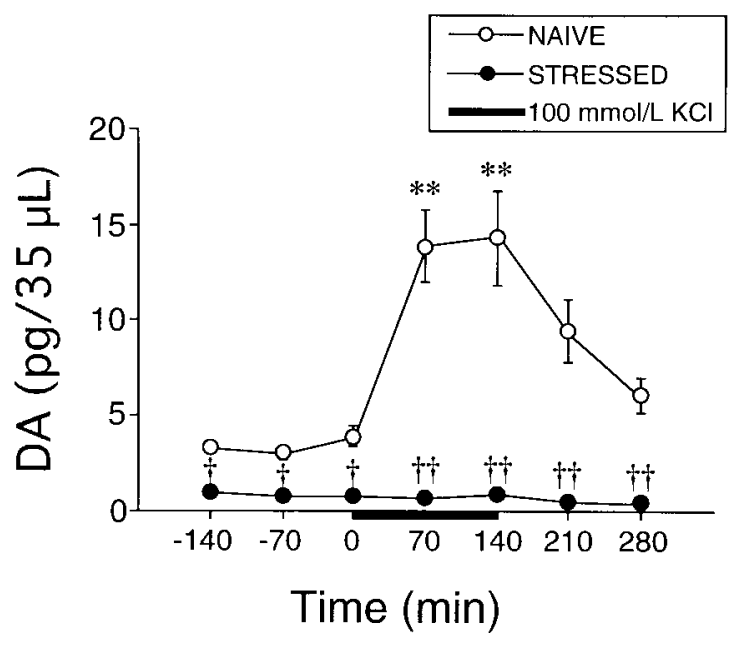

Figure 2. Effects of chronic stress on the basal and KCl-stimulated DA releases in the PFC. Each point is the mean \pm SEM of six or seven rats per group. ${ }^{* * *} p<0.001$, significant difference from naive basal levels ( -140 to 0 min); $\uparrow p<0.01, \dagger \dagger p<0.001$, significant difference from naive nonstressed rats.

The HVA level was still increased at week $2\left(F_{(4,40)}=4.18 ; p<\right.$ $0.01)$. However, at weeks 3 and 4 , the DA levels were significantly decreased (week $3, F_{(4,40)}=9.98, p<0.05$; week $4, F_{(4,40)}=9.98$, $p<0.001$ ), and the DOPAC and HVA levels returned to initial values. At day 10 of recovery, the levels of DA, DOPAC, and HVA were still significantly decreased in the chronically stressed rats $\left(\mathrm{DA}, F_{(4,40)}=9.98, p<0.01\right.$; DOPAC, $F_{(4,40)}=4.29, p<$ $\left.0.001 ; \operatorname{HVA}, F_{(4,40)}=4.18, p<0.01\right)$.

\section{$D A D 1$ receptor}

Schatchard analysis and the saturation data of $\left[{ }^{3} \mathrm{H}\right] \mathrm{SCH} 23390$ binding for the membrane preparations derived from the PFC are shown in Figure 3. $B_{\max }$ and $K_{\mathrm{d}}$ values are presented in Table 2. The $B_{\max }$ in the chronically stressed rats was significantly higher than that in the naive nonstressed rats $\left(F_{(1,16)}=4.99 ; p<0.05\right)$. There was no significant difference in the $K_{\mathrm{d}}$ value between the chronically stressed and naive nonstressed rats $\left(F_{(1,16)}=0.022\right.$; $p=0.883)$.

\section{The number of $D A$ neurons}

Because the PFC is highly innervated by dopaminergic fibers originating from the VTA (Fluxe et al., 1974), we evaluated the number of DA neurons, as identified by a TH immunostaining, in the VTA of chronically stressed rats (Table 3 ). The numbers of DA neurons in the VTA were not changed between chronically stressed and naive nonstressed rats $\left(F_{(1,8)}=0.659 ; p=0.440\right)$.

\section{DISCUSSION}

\section{Chronic stress induces working memory impairment via a D1 receptor-mediated hypodopaminergic mechanism in the PFC}

Our results showed that chronic stress induced impairment of spatial working memory via a D1 receptor-mediated hypodopaminergic mechanism in the PFC. In the delayed-alternation task, all experimental groups showed the same levels of performance accuracy under the no-delay condition (Fig. 1), suggesting that motivation, motor function, or previously acquired long-term memory for efficient rewarding in the T-maze task, i.e., reference memory, were not affected by chronic stress exposure or agent treatments. However, the performance accuracy in the chronically stressed rats markedly decreased along with the prolongation of the delay time (Fig. 1), indicating that chronic stress impairs the maintenance of a novel short-term memory, i.e., working memory, which is the term applied to the aspect of memory responsible for the recall of information immediately after it has been presented. These results may support that chronic psychosocial stress exaggerates the acquisition of working memory (Krugers et al., 1997). The findings that intra-PFC infusion of SKF 81297 produced a dose-dependent amelioration of the stress-induced working memory impairment suggest that this impairment is caused by the reduced D1 receptor stimulation. The reversal of the D1 receptor agonist response by D1 receptor antagonist SCH 23390 confirms actions at the D1 receptor rather than nonspecific drug actions. The doses of SKF 81297 having a partial or sufficient improving effect on the stress-induced working memory impairment (i.e., 1 or $10 \mathrm{ng}$ ) were relatively low compared with that which produces a working memory impairment in rats (i.e., $100 \mathrm{ng}$ ) (Zahrt et al., 1997) and did not affect the working memory of the naive control rats. These results are consistent with the observation in aged monkeys with naturally occurring DA depletion (Arnsten et al., 1994; Cai and Arnsten, 1997). Thus, a low dose (e.g., $100 \mathrm{ng} / \mathrm{kg}$ ) of SKF 81297 improves spatial working memory. In addition, these doses of SKF 81297 were within the extent of the proper dose-response relationship of D1 receptor agonist for the working memory performance (Zahrt et al., 1997).

The neurochemical studies on the dopaminergic neuronal activity in the PFC of the stressed rats revealed that short-term stress ( 1 week) activated the dopaminergic neurons in the PFC (Table 1), which supports that the hyperdopaminergic mechanism is behind the acute stress-induced cognitive deficits (Arnsten and Goldman-Rakic, 1998). However, these activations were not observed in the long-term stressed (4 weeks) PFC (Table 1), and the stressed and recovered rats showed greatly reduced DA transmission (Table 1, Fig. 2). DA D1 receptors are located postsynaptically on the cortical neurons (Tassin et al., 1978, 1982), and the

Table 1. Time course changes in the contents of DA and its metabolites in the PFC during a 4 week stress session and a $10 \mathrm{~d}$ recovery period

\begin{tabular}{|c|c|c|c|c|c|c|}
\hline & \multicolumn{6}{|l|}{ Stress period } \\
\hline & $0 \mathrm{~W}$ & $1 \mathrm{~W}$ & $2 \mathrm{~W}$ & $3 \mathrm{~W}$ & $4 \mathrm{~W}$ & $4 \mathrm{~W}+10 \mathrm{~d}$ \\
\hline DA & $1150.0 \pm 113.5$ & $1342.1 \pm 168.8$ & $1435.8 \pm 118.5$ & $719.7 \pm 104.5^{*}$ & $585.3 \pm 70.2^{* * *}$ & $696.0 \pm 63.8^{* *}$ \\
\hline DOPAC & $80.2 \pm 7.8$ & $133.4 \pm 11.8^{* *}$ & $112.6 \pm 10.4$ & $105.3 \pm 14.5$ & $75.8 \pm 11.9$ & $55.7 \pm 5.2^{* * *}$ \\
\hline HVA & $57.5 \pm 4.6$ & $89.6 \pm 8.6^{* *}$ & $88.5 \pm 7.5^{* *}$ & $70.9 \pm 9.1$ & $56.8 \pm 8.5$ & $39.1 \pm 5.2^{* *}$ \\
\hline
\end{tabular}

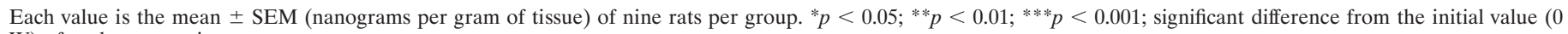
W) of each monoamine. 

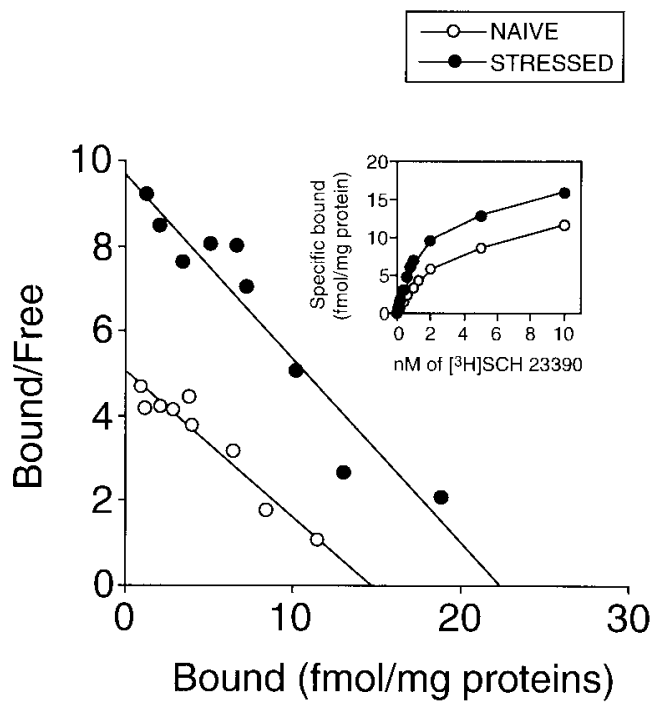

Figure 3. Saturation and Schatchard plot analyses for the density and affinity of DA D1 receptors in the PFC of chronically stressed and naive nonstressed rats. Each point is the mean of six or seven rats per group. There is a significant difference on the receptor density between stressed and naive nonstressed rats $(p<0.05)$.

\section{Table 2. $\left[{ }^{3} \mathrm{H}\right] \mathrm{SCH} 23390$ binding in the PFC}

\begin{tabular}{|c|c|c|}
\hline & \multirow{2}{*}{$\frac{B_{\max }}{(\mathrm{fmol} / \mathrm{mg} \text { protein })}$} & \multirow{2}{*}{$\frac{K_{\mathrm{d}}}{(\mathrm{nmol} / \mathrm{l})}$} \\
\hline & & \\
\hline Naive & $14.5 \pm 2.9$ & $3.4 \pm 0.7$ \\
\hline Stressed & $22.3 \pm 3.5^{*}$ & $3.3 \pm 0.5$ \\
\hline
\end{tabular}

Each value is the mean \pm SEM of six or seven rats per group. ${ }^{*} p<0.05$; significant difference from naive nonstressed rats.

\section{Table 3. TH-positive cells in the VTA}

Number of TH-positive cells (/whole sections)

\begin{tabular}{ll}
\hline Naive & $249.2 \pm 36.6$ \\
Stressed & $234.6 \pm 37.9$
\end{tabular}

Each value is the mean \pm SEM of four rats per group.

decreased DA level in the PFC induced by electrolytic lesion upregulates the D1 receptor density in the PFC (Tassin et al., 1982). Conversely, long-term administration of D1 receptor agonist SKF 38393 downregulates the D1 receptor density in the PFC (Gambarana et al., 1995). Therefore, the finding that the D1 receptors were upregulated in the PFC of the chronically stressed rats (Fig. 3, Table 2) suggests reduced DA transmission at the receptor level and confirms the improving effects of SKF 81297. Taken together, the results from this series of experiments confirm the hypothesis that chronic stress-induced memory impairment occurs via a DA D1 receptor-mediated hypodopaminergic mechanism in the PFC. Thus, an exposure to acute stress impairs PFC cognitive function through a hyperdopaminergic mechanism (Arnsten and Goldman-Rakic, 1998), but that to chronic stress impairs this function through a hypodopaminergic mechanism (present study). The chronic stress-induced PFC dysfunctions might be expressed as an organic abnormality, because these dysfunctions were observed on day 10 of recovery after the 4 week stress session. A reduced DA synthesis in the originating area might not contribute to this dysfunction because there was no marked change in the number of DA neurons in the VTA of the chronically stressed rats. In addition, the chronic stressinduced dopaminergic dysfunction appears to mainly occur at presynaptic sites of the dopaminergic neurons in the PFC, given the loss of $\mathrm{DA}$ response on stimulation by $\mathrm{KCl}$, a depolarizational reagent, and upregulation of D1 receptors located at postsynaptic sites. Although previous reports have indicated that DA D2 receptors (Verma and Moghaddam, 1996) and glutamate and GABA receptors in the PFC (Izquierdo et al., 1998) or D1, glutamate, GABA, and cholinergic muscarinic receptors in the hippocampus (Izquierdo et al., 1998) may also regulate working memory, our findings suggest that D1 receptor stimulation is sufficient to improve the stress-induced working memory impairment.

The factors that modulate the stress-induced dopaminergic dysfunction in the PFC are unknown. It is possible that some stress-sensitive neurotransmitters or hormones contribute to the dysfunction. For example, GABA (Hegarty and Vogel, 1995), norepinephrine (Gresch et al., 1993), and glutamate (Jedema and Moghaddam, 1994) can modulate the activity of DA neurons during stress response. Considering that long-term stress period was required for the expression of stress-induced dopaminergic dysfunction, as indicated in the time course study (Table 1), another factor with long-term effects such as glucocorticoids may be implicated in the dysfunction. Glucocorticoid secretion is potently activated by exposure to acute stress, such as immobilization stress (Sapolsky et al., 1984a) and water immersion and restraint (K. Mizoguchi, unpublished observations). Mesencephalic dopaminergic neurons have glucocorticoid receptors (Härfstrand et al., 1986), and the administration of glucocorticoids can modify DA metabolism (Versteeg et al., 1983; Rothschild et al., 1985) and increases the DA release in the PFC (Imperato et al., 1989). Conversely, suppression of endogenous glucocorticoids by adrenalectomy reduces the DA transmission in the nucleus accumbens under both basal and morphine-, a depolarizational agent, stimulative conditions with no change in the number of DA neurons in the VTA (Piazza et al., 1996). Adrenalectomy also reduces the DA transmission in the PFC (Mizoguchi, unpublished observations). Sapolsky et al. (1984b) have demonstrated that chronic immobilization stress downregulates glucocorticoid receptors in the brain. Furthermore, rats that were chronically exposed to footshock stress showed a decreased sensitivity to glucocorticoid negative feedback, indicating the involvement of glucocorticoid receptor downregulation (Young et al., 1990). Therefore, it is conceivable that part of the actions is mediated through the glucocorticoid receptor reduction in the chronically stressed rat brains.

\section{Clinical relevance}

The response of the CNS to stress is often critical to the adaptation of an organism to a stressful environment. However, in humans, an overresponse to stress can be maladaptive, resulting in the expression or exacerbation of many neuropsychiatric disorders, including a number of features that indicate abnormal functioning of the PFC (Mattes, 1980; Weinberger et al., 1986; Deutch, 1993; Fibiger, 1995). The influence of dopaminergic neurons in the PFC on the PFC functions in neuropsychiatric disorders remains obscure, but some observations support the idea that these neurons play a role in the pathogenesis of certain neuropsychiatric disorders. For example, depression is thought to 
be induced by chronic stress, and Dolan et al. (1994) have provided evidence that neuropsychological symptoms, including cognitive deficits in depression, are associated with profound hypometabolism, particularly involving the medial PFC. A similar observation has been reported that both bipolar and unipolar depressives are identified by decreases in cerebral blood flow and rate of glucose metabolism in the PFC (Drevets et al., 1997). Furthermore, agents that enhance DA transmission, e.g., buproprion, have been used as successful antidepressants (Calabrese and Markovitz, 1991). Several other antidepressants such as fluoxetine, clomipramine, imipramine, and desipramine also increase extracellular DA concentrations in the rat PFC (Tanda et al., 1994), indicating that the PFC is a target site of antidepressants. These findings suggest that reduced DA transmission in the PFC is implicated in the pathogenesis of depression. A similar relationship has been suggested in patients with Parkinson's disease accompanied by depression (Cummings, 1992; Deutch, 1993). Depression occurs in large populations of patients with Parkinson's disease, and depressed patients with Parkinson's disease have greater frontal lobe dysfunction and greater involvement of a reduced dopaminergic system than nondepressed patients with the disease. In addition, negative or defect symptoms of schizophrenia, such as not only impaired working memory but also low volition, social withdrawal, and impaired insight and judgment are suspected to be attributable to the reduced dopaminergic transmission in the PFC (Knable and Weinberger, 1997). Thus, dopaminergic neurons in the PFC are thought to play an important role in many neuropsychic activities, including working memory. Although we have not evaluated other neuropsychic activities of the chronically stressed rats in the present study, the significance of the dopaminergic neuronal dysfunction induced by chronic stress would not be confined to working memory impairment and might include the disruptions of other neuropsychic activities in stress-related neuropsychiatric disorders.

In conclusion, exposure to chronic stress is sufficient to produce PFC dysfunction as a disorder of organic function. Although the mechanism behind the vulnerability of PFC DA neurons to stress remains to be studied, this finding provides an important information for the treatment and prevention of stress-related neuropsychiatric disorders.

\section{REFERENCES}

Abercrombie ED, Keefe KA, di Frischia DS, Zigmond MJ (1989) Differential effect of stress on in vivo dopamine release in striatum, nucleus accumbens, and medial frontal cortex. J Neurochem 52:1655-1658.

Andersen PH, Jansen JA (1990) Dopamine receptor agonists: selectivity and D1 receptor efficacy. Eur J Pharmacol 188:335-347.

Arnsten ATF, Cai JX, Murphy BL, Goldman-Rakic PS (1994) Dopamine D1 receptor mechanisms in the cognitive performance of young adult and aged monkeys. Psychopharmacology (Berl) 116:143-151.

Arnsten AFT, Goldman-Rakic PS (1986) Reversal of stress-induced delayed response deficits in rhesus monkeys by clonidine and naloxone. Soc Neurosci Abstr 12:1464.

Arnsten AFT, Goldman-Rakic PS (1998) Noise stress impairs prefrontal cortical cognitive function in monkeys. Arch Gen Psychiatry 55:362-368.

Billard W, Ruperto V, Crosby G, Iorio LC, Barnett A (1984) Characterization of the binding of $3 \mathrm{H}-\mathrm{SCH} 23390$, a selective D-1 receptor antagonist ligand, in rat striatum. Life Sci 35:1885-1893.

Bossé R, DiPaolo T (1996) The modulation of brain dopamine and GABAA receptors by estradiol: a clue for CNS changes occurring at menopause. Cell Mol Neurobiol 16:199-212.

Brozoski TJ, Brown RM, Rosvold HE, Goldman PS (1979) Cognitive deficit caused by regional depletion of dopamine in prefrontal cortex of rhesus monkey. Science 205:929-932.

Brzozowski T, Konturek SJ, Majka J, Dembinski A, Drozdowicz D (1993) Epidermal growth factor, polyamines, and prostaglandins in healing of stress-induced gastric lesions in rats. Dig Dis Sci 38:276-283.

Bubser M, Schmidt WJ (1990) 6-Hydroxydopamine lesion of the rat prefrontal cortex increases locomotor activity, impairs acquisition of delayed alternation tasks, but does not affect uninterrupted tasks in the radial maze. Behav Brain Res 37:157-168.

Cai JX, Arnsten ATF (1997) Dose-dependent effects of the dopamine D1 receptor agonists A77636 or SKF 81297 on spatial working memory in aged monkeys. J Pharmacol Exp Ther 282:1-7.

Calabrese JR, Markovitz PJ (1991) Treatment of depression. New pharmacologic approaches. Prim Care 18:421-433.

Cummings JL (1992) Depression and Parkinson's disease: a review. Am J Psychiatry 149:443-454.

Deutch AY (1993) Prefrontal cortical dopamine systems and the elaboration of functional corticostriatal circuits: implications for schizophrenia and Parkinson's disease. J Neural Transm 91:197-221.

Dolan RJ, Bench CJ, Brown RG, Scott LC, Frackowiak RS (1994) Neuropsychological dysfunction in depression: the relationship to regional cerebral blood flow. Psychol Med 24:849-857.

Drevets WC, Price JL, Simpson Jr JR, Todd RD, Reich T, Vannier M, Raichle ME (1997) Subgenual prefrontal cortex abnormalities in mood disorders. Nature 386:824-827.

Fibiger HC (1995) Neurobiology of depression: focus on dopamine. Adv Biochem Psychopharmacol 49:1-17.

Fluxe K, Hökfelt T, Johansson O, Jonnson G, Lidbrink P, Ljungdal A (1974) The origin of DA nerve terminals in limbic and frontal cortex. Evidence for mesocortical neurons. Brain Res 82:349-355.

Gambarana C, Ghiglieri O, Graziella de Montis M (1995) Desensitization of the D1 dopamine receptors in rats reproduces a model of escape deficit reverted by imipramine, fluoxetine and clomipramine. Prog Neuropsychopharmacol Biol Psychiatry 19:741-755.

Gresch PJ, Sved AF, Zigmond MJ, Finlay JM (1993) Local application of desipramine increases basal and stress-induced dopamine efflux in medial prefrontal cortex. Soc Neurosci Abstr 19:1828.

Gresch PJ, Sved AF, Zigmond MJ, Finlay JM (1994) Stress-induced sensitization of dopamine and norepinephrine efflux in medial prefrontal cortex of the rats. J Neurochem 63:575-583.

Härfstrand A, Fuxe K, Cintra A, Agnati LF, Zini I, Wikstrom AC, Okret S, Yu ZY, Goldstein M, Steinbusch H, Verhofstad A, Gustafsson JA (1986) Glucocorticoid receptor immunoreactivity in monoaminergic neurons of rat brain. Proc Natl Acad Sci USA 83:9779-9783.

Hegarty AA, Vogel WH (1995) The effect of acute and chronic diazepam treatment on stress-induced changes in cortical dopamine in the rat. Pharmacol Biochem Behav 52:771-778.

Imperato A, Puglisi-Allegra S, Casolini P, Zocchi A, Angelucci L (1989) Stress-induced enhancement of dopamine and acetylcholine release in limbic structure: role of corticosterone. Eur J Pharmacol 165:337-339.

Izquierdo I, Izquierdo LA, Barros DM, Mello e Souza T, de Souza MM, Quevedo J, Rodrigues C, Sant'Anna MK, Madruga M, Medina JH (1998) Differential involvement of cortical receptor mechanisms in working, short-term and long-term memory. Behav Pharmacol 9:421-427.

Jedema HP, Moghaddam B (1994) Glutametargic control of dopamine release during stress in the rat prefrontal cortex. J Neurochem 63:785-788.

Knable MB, Weinberger DR (1997) Dopamine, the prefrontal cortex and schizophrenia. J Psychopharmacol 11:123-131.

Konturek SJ, Brzozowski T, Drozdowicz D, Krzyzek E, Garlicki J, Majka J, Dembinski A, Stachura J, Amon I (1991) Nocloprost, a unique prostaglandin E2 analog with local gastroprotective and ulcer-healing activity. Eur J Pharmacol 195:347-357.

Krugers HJ, Douma BR, Andringa G, Bohus B, Korf J, Luiten PG (1997) Exposure to chronic psychosocial stress and corticosterone in the rat: effects on spatial discrimination learning and hippocampal protein kinase C gamma immunoreactivity. Hippocampus 7:427-436.

Lange KW, Robbins TW, Marsden CD, James M, Owen AM, Paul GM (1992) L-dopa withdrawal in Parkinson's disease selectively impairs cognitive performance in tests sensitive to frontal lobe dysfunction. Psychopharmacology (Berl) 107:394-404.

Lowry OH, Rosebrough NJ, Farr AL, Randall RJ (1951) Protein measurement with the foline phenol reagent. J Biol Chem 193:265-275. 
Markowitsch HJ, Pritzel M (1977) Comparative analysis of prefrontal learning functions in rats, cats, and monkeys. Psychol Bull 84:817-837.

Mattes JA (1980) The role of frontal lobe dysfunction in childhood hyperkinetics. Comp Psychiatry 21:358-369.

Mazure CM (1995) Does stress cause psychiatric illness? In: Progress in Psychiatry (Spiegel D, ed), pp 270-298. Washington, DC: American Psychiatric.

Mizoguchi K, Kunishita T, Chui DH, Tabira T (1992) Stress induces neuronal death in the hippocampus of castrated rats. Neurosci Lett 138:157-160.

Moran PM (1993) Differential effects of scopolamine and mecamylamine on working and reference memory in the rats. Pharmacol Biochem Behav 45:533-538.

Murphy BL, Arnsten ATF, Goldman-Rakic PS, Roth RH (1996a) Increased dopamine turnover in the prefrontal cortex impairs spatial working memory performance in rats and monkeys. Proc Natl Acad Sci USA 96:1325-1329.

Murphy BL, Arnsten ATF, Jentsch JD, Roth RH (1996b) Dopamine and spatial memory in rats and monkeys: pharmacological reversal of stressinduced impairment. J Neurosci 16:7768-7775.

Paxinos G, Watson C (1982) The rat brain in stereotaxic coordinates. New York: Academic Press.

Piazza PV, Barrot M, Rougé-Pont F, Marinelli M, Maccari S, Abrous N, Simon H, le Moal M (1996) Suppression of glucocorticoid secretion and antipsychotic drugs have similar effects on the mesolimbic dopaminergic transmission. Proc Natl Acad Sci USA 93:15445-15450.

Rothschild AJ, Langlais PJ, Schatzberg AF, Miller MM, Saloman MS, Lerbinger JE, Cole JO, Bird ED (1985) The effect of a single acute dose of dexamethasone on monoamine and metabolite levels in the rat brain. Life Sci 36:2491-2505.

Sapolsky RM, Krey LC, McEwen BS (1984a) Glucocorticoid-sensitive hippocampal neurons are involved in terminating the adrenocortical stress response. Proc Natl Acad Sci USA 81:6174-6177.

Sapolsky RM, Krey LC, McEwen BS (1984b) Stress down-regulates corticosterone receptors in a site specific manner in the brain. Endocrinology 114:287-292.

Sawaguchi T, Goldman-Rakic PS (1991) D1 dopamine receptors in prefrontal cortex: involvement in working memory. Science 251:947-950.

Schwab RS, Zieper I (1965) Effects of mood, motivation, stress, and alertness on the performance in Parkinson's disease. Psychiat Neurol (Basel) 150:345-357.

Seamans JK, Floresco SB, Phillips AG (1995) Selective impairment on a delay radial arm task following local administration of a selective D1, but not a D2, antagonist into the prefrontal cortex. Soc Neurosci Abstr 21:1942.

Simon H, Scatton B, le Moal M (1980) Dopaminergic A-10 neurons are involved in cognitive functions. Nature 286:150-151.

Takahashi A, Ishimaru H, Ikarashi Y, Maruyama Y (1993) Intraventricular injection of neostigmine increases dopaminergic and noradrenergic nerve activities: hyperglycemic effects and neurotransmitters in the hypothalamus. Neurosci Lett 156:54-56.

Tanda G, Carboni E, Frau R, Di Chiara G (1994) Increase of extracellular dopamine in the prefrontal cortex: a trait of drugs with antidepressant potential? Psychopharmacology (Berl) 115:285-288.

Tassin JP, Bockaert J, Blanc G, Stinus L, Thierry AM, Lavielle S, Prémont J, Glowinski J (1978) Topographical distribution of dopaminergic innervation and dopaminergic receptors of the anterior cerebral cortex of the rats. Brain Res 154:241-251.

Tassin JP, Simon H, Hervé D, Blanc G, le Moal M, Glowinski J, Bockaert, J (1982) Non-dopaminergic fibers may regulate dopamine-sensitive adenylate cyclase in the prefrontal cortex and the nucleus accumbens. Nature 259:696-698.

Van Haaren F, De Bruin JP, Heinsbroek RP, Van de Poll NE (1985) Delayed spatial response alternation: effects of delay-interval duration and lesions of the medial prefrontal cortex on response accuracy of male and female Wistar rats. Behav Brain Res 18:41-49.

Verma A, Moghaddam B (1996) NMDA receptor antagonists impair prefrontal cortex function as assessed via spatial delayed alternation performance in rats: modulation by dopamine. J Neurosci 16:373-379.

Versteeg DHG, van Zoest I, de Kloet ER (1983) Acute changes in dopamine metabolism in the medial basal hypothalamus following adrenalectomy. Experientia 40:112-114.

Watanabe Y, Gould E, McEwen BS (1992) Stress induces atrophy of apical dendrites of hippocampal CA3 pyramidal neurons. Brain Res 588:341-345.

Weinberger DR, Berman KF, Zec RF (1986) Physiologic dysfunction of dorsolateral prefrontal cortex in schizophrenia, I: regional cerebral blood flow evidence. Arch Gen Psychiatry 43:114-124.

Young EA, Akana S, Dallman MF (1990) Decreased sensitivity to glucocorticoid fast feedback in chronically stressed rats. Neuroendocrinology 51:536-542.

Zahrt J, Taylor JR, Mathew RG, Arnsten AFT (1997) Supranormal stimulation of D1 dopamine receptors in the rodent prefrontal cortex impairs spatial working memory performance. J Neurosci 17:85288535. 